\title{
Genetic modification of alternative respiration in Nicotiana benthamiana affects basal and salicylic acid-induced resistance to potato virus $X$
}

\author{
Wing-Sham Lee ${ }^{1 \dagger}$, Shih-Feng $\mathrm{Fu}^{1 \dagger}$, Jeanmarie Verchot-Lubicz ${ }^{2}$, John P Carr ${ }^{1 *}$
}

\begin{abstract}
Background: Salicylic acid (SA) regulates multiple anti-viral mechanisms, including mechanism(s) that may be negatively regulated by the mitochondrial enzyme, alternative oxidase (AOX), the sole component of the alternative respiratory pathway. However, studies of this mechanism can be confounded by SA-mediated induction of RNA-dependent RNA polymerase 1, a component of the antiviral RNA silencing pathway. We made transgenic Nicotiana benthamiana plants in which alternative respiratory pathway capacity was either increased by constitutive expression of AOX, or decreased by expression of a dominant-negative mutant protein (AOX-E). N. benthamiana was used because it is a natural mutant that does not express a functional RNA-dependent RNA polymerase 1.

Results: Antimycin A (an alternative respiratory pathway inducer and also an inducer of resistance to viruses) and SA triggered resistance to tobacco mosaic virus (TMV). Resistance to TMV induced by antimycin A, but not by SA, was inhibited in Aox transgenic plants while SA-induced resistance to this virus appeared to be stronger in Aox-E transgenic plants. These effects, which were limited to directly inoculated leaves, were not affected by the presence or absence of a transgene constitutively expressing a functional RNA-dependent RNA polymerase (MtRDR1). Unexpectedly, Aox-transgenic plants infected with potato virus X (PVX) showed markedly increased susceptibility to systemic disease induction and virus accumulation in inoculated and systemically infected leaves. SA-induced resistance to PVX was compromised in Aox-transgenic plants but plants expressing AOX-E exhibited enhanced SA-induced resistance to this virus.

Conclusions: We conclude that AOX-regulated mechanisms not only play a role in SA-induced resistance but also make an important contribution to basal resistance against certain viruses such as PVX.
\end{abstract}

\section{Background}

Salicylic acid (SA) is an important defensive signal in plants that is required for elicitor-triggered immunity and the establishment of systemic acquired resistance (SAR) [1-8]. Plants exhibiting SAR possess an enhanced state of protection against a broad spectrum of pathogens, including viruses, oomycetes, fungi and bacteria $[3,5]$. SA inhibits various phases of the viral life cycle including replication, cell-to-cell movement and systemic movement. However, the precise effects of SA can differ between various host-virus combinations [9-16].

\footnotetext{
* Correspondence: jpc1005@hermes.cam.ac.uk

+ Contributed equally

'Department of Plant Sciences, University of Cambridge, Downing Street,

Cambridge CB2 3EA, UK

Full list of author information is available at the end of the article
}

RNA silencing (also known as post-transcriptional gene silencing) is thought likely to contribute to SA-induced virus resistance although it is unlikely to be the only mechanism involved [17]. RNA silencing is a sequencespecific mechanism regulating the synthesis, stability, and translatability of mRNA molecules that is guided by small RNA molecules in the size range 21-26 nt [reviewed in ref. [18]]. The involvement of RNA silencing in SA-induced virus resistance was first suggested by the discovery that SA can induce expression of a component of the RNA silencing machinery, RNA-directed RNA polymerase 1 (RDR1) [19]. RDR1 may also contribute to defense through regulation of host mRNAs encoding other defensive factors, for example those involved in jasmonic acid-induced defenses [19-24]. Additional evidence for a role for RNA silencing in SA-mediated
C Biomed Central

() 2011 Lee et al; licensee BioMed Central Ltd. This is an Open Access article distributed under the terms of the Creative Commons Attribution License (http://creativecommons.org/licenses/by/2.0), which permits unrestricted use, distribution, and reproduction in any medium, provided the original work is properly cited. 
defense arose from studies showing that viral silencing suppressor proteins, for example the cucumber mosaic virus (CMV) $2 \mathrm{~b}$ protein or HC-Pro encoded by potyviruses, interfere with SA-mediated signaling and SA biosynthesis [25-28].

There is evidence that mitochondrial signaling processes regulate some aspects of SA-induced virus resistance [discussed by [1,3]]. Reactive oxygen species (ROS) are constantly generated within mitochondria as by-products of respiratory electron transport chain activity [29-31]. Perturbation in this ROS pool or in mitochondrial redox can function in intracellular signal transduction and, through the poorly understood process of mitochondrial retrograde regulation, affect the pattern of nuclear gene expression [31-35]. This form of signaling is influenced by the alternative oxidase (AOX). AOX is a mitochondrial enzyme that is the sole component of the alternative respiratory pathway. The functions of the alternative respiratory pathway include negative regulation of mitochondrial ROS production and maintenance of primary metabolism under stress conditions [30,36-40].

Evidence supporting an additional role for mitochondrial signaling and AOX in virus resistance includes observations that non-toxic levels of respiratory inhibitors such as antimycin A or cyanide induce resistance against several plant viruses $[9,12,13,15,16,41,42]$, and that SA, which is a weak cytochrome pathway inhibitor, induces Aox1a gene expression [36,43,44]. Murphy and associates [45] found that expression of an AOX coding sequence by a TMV-derived expression vector enhanced its spread in $N$. benthamiana plants. Gilliland and colleagues [20] found that in directly inoculated leaves, SA- and antimycin A-induced resistance to TMV was transiently enhanced in transgenic plants that had decreased alternative respiratory pathway capacities. However, in transformed tobacco plants that had increased alternative respiratory pathway capacities due to constitutive expression of an Aox 1 a transgene, the induction of resistance to TMV by antimycin A was inhibited, while SA-induced resistance was not [20].

To explain these results, it was proposed that SA and antimycin A both stimulate a signaling pathway that is negatively-regulated by AOX. However, RDR1, a factor in resistance to TMV [19], is also inducible by SA but not by antimycin A $[20,46]$. Since $R D R 1$ gene expression is not affected by AOX, it was suggested that this is why an increase in alternative respiratory pathway capacity inhibits antimycin A-induced resistance but does not completely inhibit SA-induced resistance to TMV [20,46]. To further investigate the AOX-regulated mechanism of resistance to viruses we have used the experimental host plant $N$. benthamiana. This is highly susceptible to a wide range of viruses, which is explained to some extent by the fact that its $R D R 1$ ortholog, $N b R D R 1 m$, encodes an inactive enzyme [22]. Thus, $N$. benthamiana provides a natural mutant background for exploring the effect of AOX on plant responses to virus infection without the potentially confounding presence of active RDR1.

\section{Results}

\section{Construction and characterization of stably transformed}

$N$. benthamiana plants with modified alternative respiratory pathway capacity

To increase or decrease alternative respiratory pathway capacity, $N$. benthamiana plants (non-transgenic or already expressing an RDR1 transgene derived from Medicago truncatula: 22) were transformed with, respectively, either a wild-type tobacco Aox 1 a cDNA, or a mutant sequence, $A o x-E$ [45]. Aox- $E$ encodes an inactive version of AOX (AOX-E) to act as a dominant negative mutant $[45,47]$. Transgenes were fused to an enhanced cauliflower mosaic virus $35 \mathrm{~S}$ promoter to drive constitutive high-level expression (Additional File 1). Transgene expression and the respiratory characteristics of transgenic plant lines were examined $[20,40,45]$ and lines with up- or down-regulated alternative respiratory capacity were selected for subsequent experiments (Table 1).

\section{Altering alternative respiratory pathway capacity affected basal resistance to potato virus $X$}

Modifying alternative respiratory capacity had dramatic effects on disease symptoms in PVX-infected plants (Figure 1) and on virus accumulation in directly-inoculated and systemically infected leaves (Figure 2A). PVX caused mild symptoms in non-transgenic $N$. benthamiana plants but caused stunting and leaf curling symptoms in Aox-transgenic plants with increased alternative pathway capacities (Figure 1). Accumulation of PVX coat protein was higher in $A o x$-transgenic plants with than in nontransgenic plants (Figure 2A). Decreasing the alternative pathway capacity by expression of AOX-E did not appear to affect symptom development following infection with PVX (Figure 1). At 14 days post-inoculation significantly lower levels of virus had accumulated in plants expressing AOX-E than those expressing AOX $(p=0.02)$. Although at 14 days post-inoculation less virus accumulated in plants expressing AOX-E than in non-transgenic plants these differences were not statistically significant ( $\mathrm{t}$-test, $p=0.145$ ) (Figure 2B) and were not observed consistently at later time points (Figure 3). These data show that modulating alternative respiratory capacity affects PVX accumulation.

\section{Salicylic acid-induced resistance to PVX is modified in plants with increased and decreased alternative respiratory pathway capacity}

Following treatment with SA, PVX coat protein accumulation was monitored in transgenic plants from lines 
Table 1 Alternative respiratory pathway capacity in transgenic plant lines expressing AOX or AOX-E that were used in this study

\begin{tabular}{|c|c|c|c|c|c|c|c|}
\hline \multirow[b]{2}{*}{ Plant Line ${ }^{1}$} & \multirow[b]{2}{*}{ Transgene(s) } & \multicolumn{6}{|c|}{ Oxygen Consumption Rates $\left(\mathrm{nmol} \mathrm{O}_{2} \mathrm{~min}^{-1} / 10^{6} \text { cell) }\right)^{2}$} \\
\hline & & Control & Antimycin A & Antimycin A + SHAM & Corrected Control $^{3}$ & AP Capacity ${ }^{4}$ & $\mathrm{n}$ \\
\hline NT & - & $1.86 \pm 0.08$ & $1.43 \pm 0.01$ & $0.04 \pm 0.04$ & 1.82 & 1.39 & 8 \\
\hline AOX1 & 35S:Aox1a & $5.35 \pm 0.36$ & $6.08 \pm 0.68$ & $0.79 \pm 0.13$ & 4.57 & 5.30 & 3 \\
\hline AOX3 & 35S:Aox1a & $3.38 \pm 0.33$ & $4.62 \pm 0.54$ & $0.54 \pm 0.11$ & 2.83 & 4.07 & 3 \\
\hline AOX-E3 & 35S:Aox-E & $2.03 \pm 0.28$ & $0.77 \pm 0.13$ & $0.39 \pm 0.06$ & 1.64 & 0.39 & $\overline{4}$ \\
\hline AOX-E5 & 35S:Aox-E & $1.68 \pm 0.11$ & $0.73 \pm 0.11$ & $0.18 \pm 0.02$ & 1.50 & 0.55 & 3 \\
\hline Empty vector control & - & $2.18 \pm 0.27$ & $1.34 \pm 0.11$ & $0.29 \pm 0.03$ & 1.89 & 1.05 & 4 \\
\hline $\mathrm{RD} / \mathrm{AOX} 2$ & 35S:Aox1a/ 35S:MtRDR1 & $1.99 \pm 0.06$ & $2.47 \pm 0.13$ & $0.065 \pm 0.003$ & 1.93 & 2.41 & 3 \\
\hline $\mathrm{RD} / \mathrm{AOX} 22$ & 35S:Aox1a/ 35S:MtRDR1 & $2.08 \pm 0.03$ & $2.55 \pm 0.01$ & $0.105 \pm 0.024$ & 1.98 & 2.45 & 3 \\
\hline
\end{tabular}

\section{Notes.}

${ }^{1}$ Leaf cells isolated from non-transgenic (NT) Nicotiana benthamiana plants, transgenic plants expressing Aox1a or Aox- $E$ sequences under the control of the cauliflower mosaic virus 35S promoter, plants harboring a 35S:MtRDR1 transgene super-transformed with the 35S:Aox1a transgene, or from plants transformed with an 'empty' transformation vector were placed in an oxygen electrode. The number $(n)$ of independent oxygen electrode experiments (each of which comprised three technical replicates) carried out for each plant line is indicated.

${ }^{2}$ Oxygen consumption rates ( \pm standard error of the mean) were measured in the absence (Control) or presence of $25 \mu \mathrm{M}$ antimycin $\mathrm{A}$ (an inhibitor of the cytochrome pathway) or $25 \mu \mathrm{M}$ antimycin A plus $2 \mathrm{mM}$ salicylhydroxamic acid (SHAM: an inhibitor of the alternative respiratory pathway). Rates determined when both inhibitors were present, gave a measure of residual, i.e. non-respiratory, oxygen consumption.

${ }^{3}$ Last two columns: residual values were used to derive corrected values for the control oxygen consumption rates, and oxygen consumption rates in the presence of antimycin A, which gives the alternative respiratory pathway (AP) capacity for each line.

${ }^{4} \mathrm{AP}$ capacity in plant cells expressing the Aox or Aox-E transgenes were significantly different from that observed in cells from non-transgenic plants ( $p<0.05$ : Student's t-test).

with increased or decreased alternative respiratory capacities at 28 days post-inoculation. Treatment with SA induced resistance to PVX in non-transgenic $N$. benthamiana but the treatment did not induce resistance to the virus in Aox-transgenic plants (Figure 3). However, as an inducer of resistance to PVX, SA was markedly more effective in these plants than in nontransgenic or Aox-transgenic plants, with virus accumulation decreased to barely detectable levels (Figure 3 ). These data show that in $N$. benthamiana plants, suppression of alternative respiratory pathway capacity combined with SA treatment led to greater PVX resistance and that SA-induced resistance to PVX was compromised by enhancement of alternative respiratory pathway capacity. Thus, for PVX, AOX-modulated defensive signalling is the predominant factor in the regulation of SA-induced resistance.

\section{Altering alternative respiratory pathway capacity affects chemical induction of resistance to tobacco mosaic virus in $N$. benthamiana}

Pre-treatment of non-transgenic $N$. benthamiana plants with SA inhibited TMV-induced symptom development in systemically infected tissues. However, modifying alternative respiratory pathway capacity in transgenic plants did not affect the timing or appearance of systemic disease symptoms induced by TMV regardless of whether or not the transgenic plants had been treated with SA (data not shown), similar to results in tobacco [20].
In contrast, modifying the alternative respiratory capacity of $N$. benthamiana plants did affect the induction of resistance by antimycin A and SA to TMV accumulation in directly inoculated leaf tissue (Figure 4). Leaves were infiltrated with a control solution or solutions of antimycin A or SA before inoculation with TMV. Viral coat protein accumulation in these leaves was detected by immunoblot analysis (Figure 4). In Aox-transgenic lines with increased alternative respiratory pathway capacities, antimycin A-induced resistance to TMV was inhibited (Figure 4). However, SA-induced resistance to TMV was not inhibited in these plants (Figure 4A). The concentration of SA $(2.5 \mathrm{mM})$ required to induce resistance to TMV in non-transgenic $N$. benthamiana was markedly higher than the $0.5 \mathrm{mM}$ concentration that is sufficient to induce resistance to TMV in tobacco [20] (Figure 4, compare panels $\mathrm{A}$ and $\mathrm{B}$ ). This may reflect the greater susceptibility to virus infection that is characteristic of $N$. benthamiana [48], or that inactivation of SA by conversion to its glucoside occurs more effectively in this plant [49]. However, in transgenic plants expressing AOX-E, that have a decreased capacity for alternative respiration, $0.5 \mathrm{mM} \mathrm{SA}$ was adequate to induce resistance to TMV infection even though it did not induce resistance to TMV in non-transgenic $N$. benthamiana leaves (Figure 4B). This was also seen in three other transgenic lines expressing the AOX-E mutant protein (data not shown). Thus, as was found to be the case in tobacco [20], in $N$. benthamiana AOX activity can negatively regulate the induction by SA and 


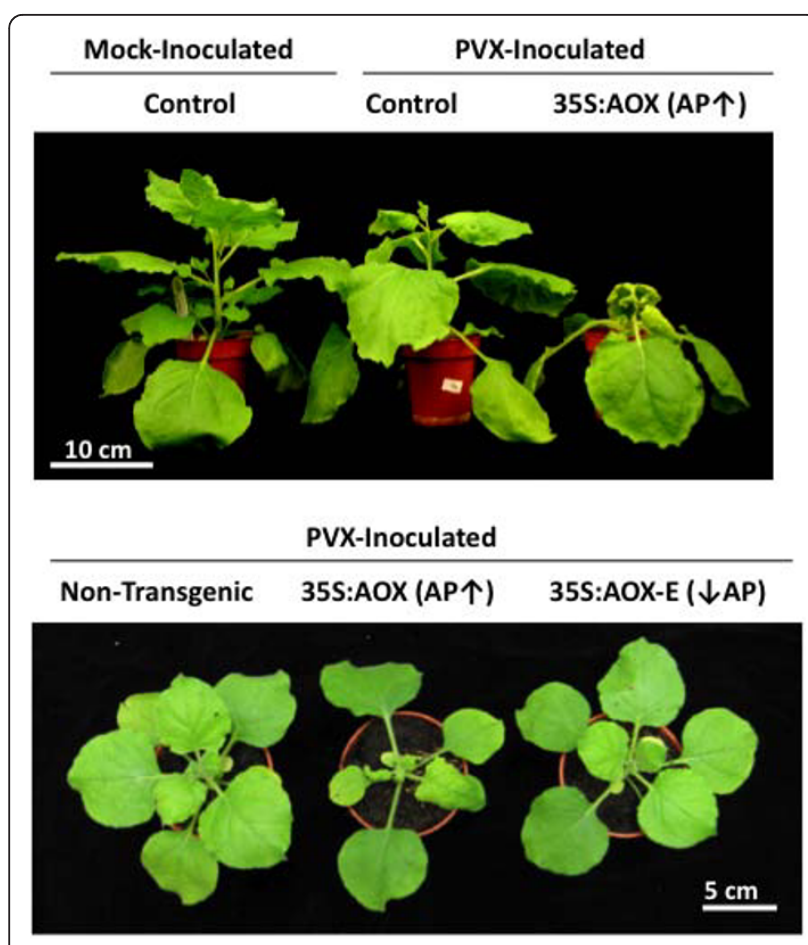

Figure 1 Increasing alternative respiratory pathway capacity exacerbates disease symptoms in potato virus $\mathrm{X}$ infected plants. Five-week-old non-transgenic plants (NT), or plants transformed with an 'empty' transformation vector (Control), and plants of transgenic lines with increased alternative respiratory pathway capacity (AP $\uparrow$ ) or decreased AP capacity (AP $\downarrow$ ) inoculated on one of the lower leaves with purified PVX $(0.5 \mu \mathrm{g} / \mathrm{ml})$ and photographed 11 days later. Compared to the effects of PVX infection on non-transgenic, transgenic control or AOX-E-transgenic plants with decreased AP capacity, increased stunting and deformation of upper leaves was evident in PVX-inoculated plants belonging to Aox-transgenic plants with increased AP capacity.

antimycin A of resistance against TMV. However, the effects of altering Aox gene expression on TMV infection overall were markedly less striking than the effects these alterations had on PVX infection.

The effects of altering Aox and RDR 1 gene expression on chemical induction of resistance to tobacco mosaic virus in $N$. benthamiana

Previously, we hypothesized that the reason that antimycin A-induced TMV resistance, but not SA-induced resistance, is inhibited in Aox-transgenic transgenic plants is because SA triggers increased expression of the antiviral enzyme RDR1, while antimycin A does not induce RDR1 $[20,46]$. We investigated the effect of constitutive RDR1 expression on chemically-induced resistance to TMV using plants doubly transformed with Aox-derived transgenes and a transgene expressing the $M$. truncatula RDR1 sequence (MtRDR1). MtRDR1-transgenic plants are more

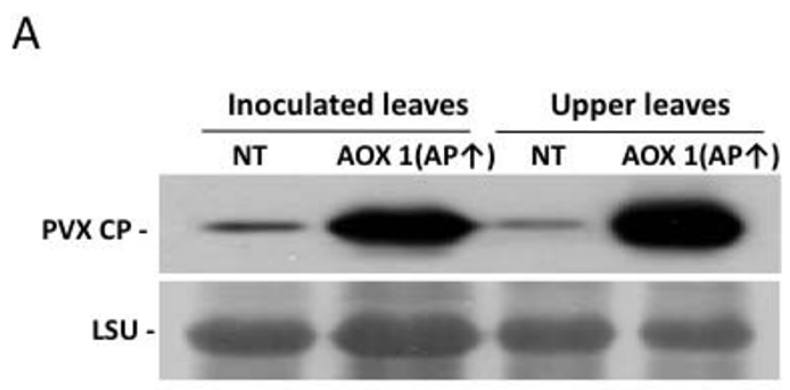

B

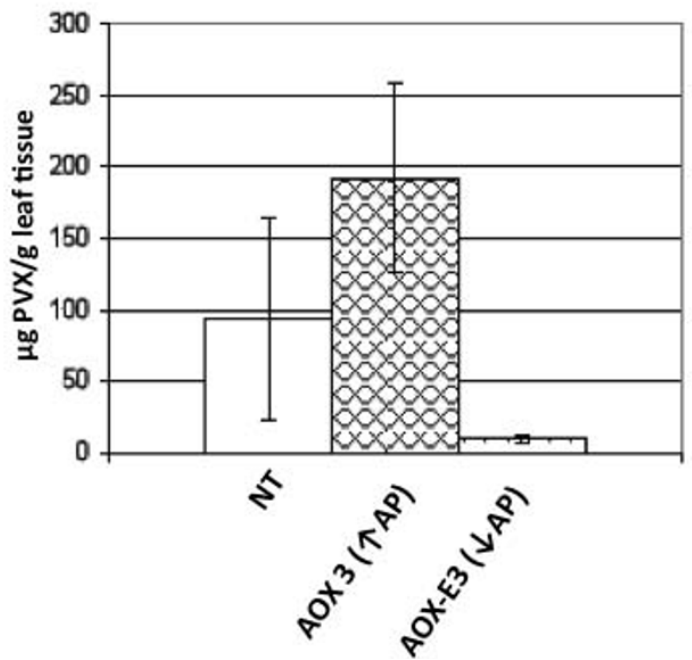

Figure 2 Susceptibility of plants to potato virus $X$ accumulation in directly inoculated and systemically infected leaves is altered by modification of alternative respiratory pathway capacity. (A) Semi-quantitative analysis of virus accumulation in PVX-inoculated non-transgenic and Aox-transgenic plants by immunoblot analysis using anti-PVX coat protein (CP). This showed that virus accumulation was higher in directly-inoculated and systemically-infected leaves of plants with increased AP capacity than in corresponding tissues of non-transgenic plants. (B) Quantitative analysis (enzyme-linked immunosorbent assay) of PVX coat protein accumulation in non-transgenic (NT) plants and plants belonging to transgenic lines with increased $(\uparrow)$ or decreased $(\downarrow)$ AP capacity. Systemically-infected (i.e., upper, not directly-inoculated) leaf tissue was harvested at 14 days post-inoculation. Tissue from the fourth leaf above the inoculated leaf was taken in each case. Using a standard curve normalized with purified PVX, mean virus concentrations per gram of leaf tissue were determined and the data from one experiment, out of a total of three independent experiments, are plotted above showing a significant (t-test, $p<$ 0.05) difference in PVX accumulation in plants with decreased AP capacity compared with those with increased AP capacity. The number of samples was six for each plant line (one sample $=$ one plant) in each treatment group. Error bars represent mean \pm standard error of the mean. 


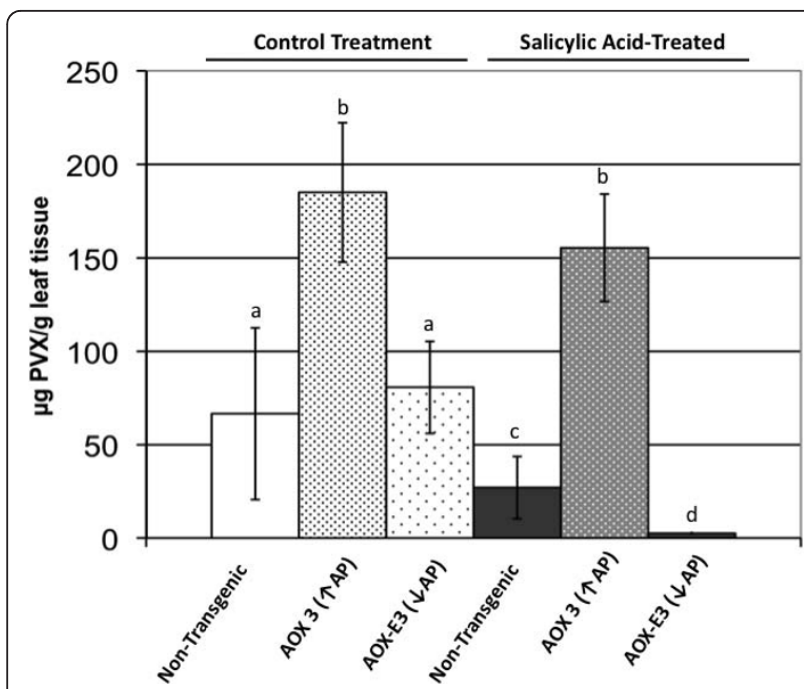

Figure 3 The effects of altering alternative respiratory pathway capacity on salicylic acid (SA)-induced resistance to potato virus X (PVX). Plants were pre-treated by spraying with a solution of SA or a control solution for four days prior to inoculation with PVX. Samples from the fourth leaf above the directly PVX-inoculated leaves of plants were harvested at 28 days post-inoculation and processed for an enzyme-linked immunosorbent assay using antiPVX coat protein serum. Mean accumulation ( $\mu \mathrm{g}$ PVX per gram of leaf tissue) was determined using a standard curve and the data from one experiment, out of a total of three independent experiments, are plotted above. The number of samples was six for each plant line (one sample = one plant) in each treatment group. Error bars represent mean \pm standard error of the mean.

Accumulation of virus was significantly different between nontransgenic and AOX 3 Aox-transgenic plants $(p=0.044)$ and between SA-treated and SA-treated AOX3 Aox-transgenic plants ( $p$ $=0.020$ ). Mean titer values labelled with the same lower case letter were not significantly different from each other (t-test, $p>0.05$ ).

resistant to TMV-induced disease and so, in contrast to transgenic control and non-transgenic plants, were not killed by systemic infection with TMV (Additional File 2 and ref. 22). However, the expression of MtRDR1 did not result in any marked effect on TMV accumulation in the directly inoculated leaves (Figure 5), suggesting that the major effect of RDR1 is to protect plants from systemic infection. Constitutive expression of MtRDR1 did not prolong the inhibitory effect of SA on TMV accumulation (Figure 5A), nor did it affect the characteristics of antimycin A-induced resistance to TMV. Although the suppression of antimycin A-induced resistance to TMV was slightly stronger in line 22 than in line 2 , in neither of these AOX-expressing lines did the constitutive expression of MtRDR1 rescue chemically-induced resistance to the virus (Figure 5B).

\section{Discussion}

In line with a model proposed by Singh and colleagues [46], modifying alternative respiration by constitutive expression of AOX or the dominant-negative mutant AOX-E affected the outcome of infection by viruses. For PVX, our data indicates that SA-induced resistance is regulated strongly by AOX and, unexpectedly, that this enzyme also plays a role in maintaining basal resistance to this virus. The interactions of these transgenic $N$. benthamiana plants with TMV are similar to those observed previously in tobacco plants transformed with Aox-derived transgenes [20,50]. Thus, as in tobacco, SAinduced resistance to TMV was enhanced in $N$. benthamiana plants with diminished alternative respiratory pathway capacity but apparently unaffected in plants with an enhanced respiratory capacity. Antimycin A-induced resistance to TMV was, respectively, enhanced or inhibited in transgenic plants in which alternative respiratory pathway capacity had been diminished or increased. However, basal resistance to TMV in $N$. benthamiana was not affected by modification of alternative respiratory capacity.

Previous studies showed that in tobacco, NtRDR1 activity contributes to the maintenance of basal resistance to PVX whilst in N. benthamiana it is NbRDR6, not NbRDR1, which is a major determinant of basal resistance against this virus $[19,22,51]$. Our data suggests that in $N$. benthamiana the defensive signal transduction pathway regulated by AOX also plays an important role in basal resistance to PVX. This result was unexpected since evidence from Gilliland and colleagues [20] had indicated that AOX-regulated defensive signaling plays no discernable role in basal resistance to TMV.

The result was further surprising since PVX, like TMV, is a positive-strand RNA virus [52]. Thus, these viruses replicate in a similar fashion, although they have differing strategies for gene expression and cell-to-cell movement [reviewed by [53]]. It may be that TMV is more effective than PVX at subverting or inhibiting the antiviral mechanisms that are regulated by AOX. TMV, for example, appears to be able to interfere with a wide range of SA-mediated responses through interaction between its replicase proteins and a transcription factor that regulates basal defense [54]. Alternatively, it may be that PVX is able to evade some of the SA-induced resistance mechanisms that inhibit TMV infection. For instance, although the accumulation of TMV and PVX was inhibited by NtRDR1, the RDR1 of Medicago truncatula inhibited TMV accumulation but PVX appears to be unaffected by this RDR1 ortholog [19,22].

Another possibility is that PVX, but not TMV, elicits a reaction similar or analogous to PAMP-triggered immunity. PAMPs or pathogen-associated molecular patterns are chemical signatures produced by cellular pathogens (bacteria, fungi, etc) that are perceived by receptor-like kinases, resulting in the triggering of localized defense responses including the generation of ROS [55]. These localized defense responses can underlie non-host 
A

\section{Experiments using $2.5 \mathrm{mM}$ SA}

\author{
Non-Transgenic \\ W \\ AA
}

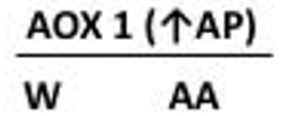

TMV CP -

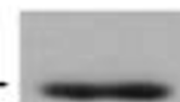

LSU -

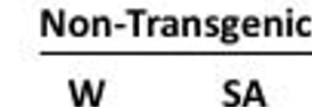

AOX 1 (个AP)

W

SA

B

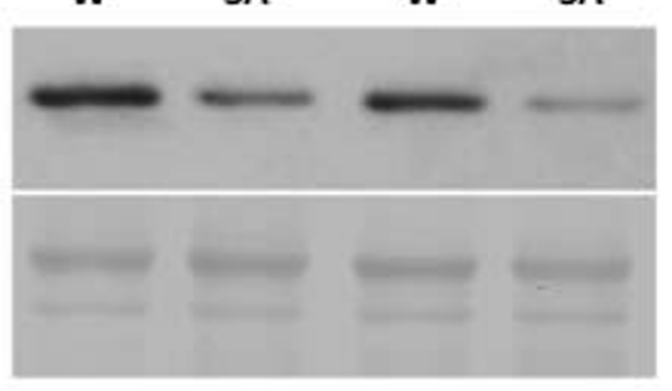

\section{Experiments using $0.5 \mathrm{mM} \mathrm{SA}$}

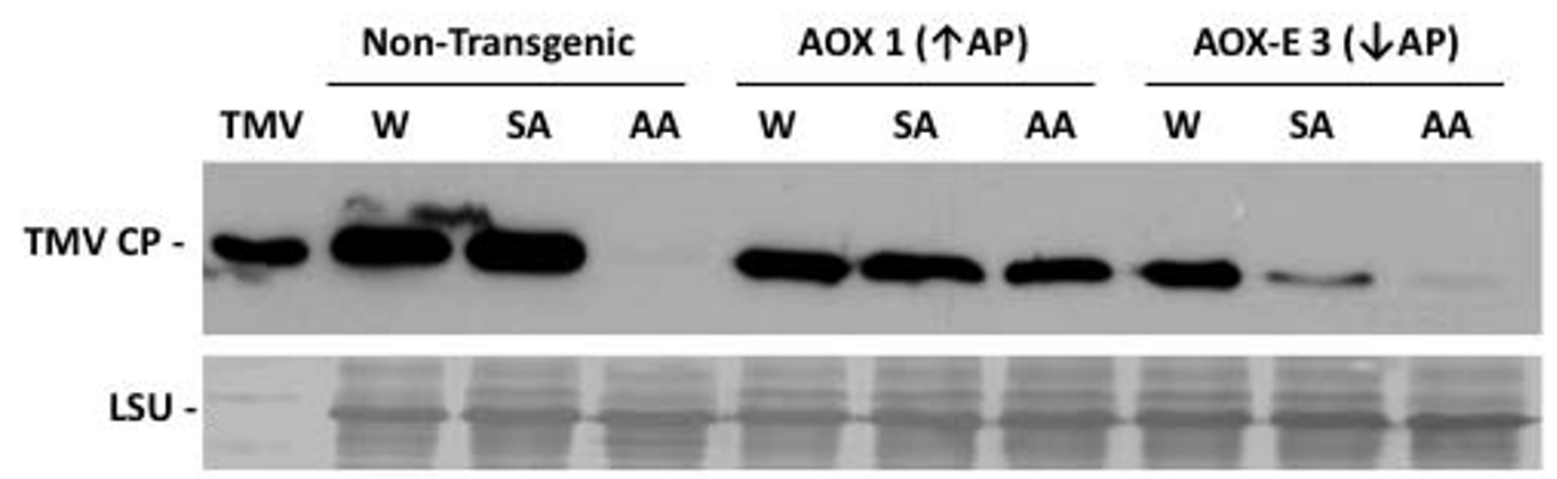

Figure 4 Modifying alternative respiratory pathway capacity affects chemical induction of resistance to tobacco mosaic virus (TMV) in inoculated leaves. TMV coat protein (CP) accumulation examined 72 hours post-inoculation by immunoblotting using anti-TMV CP serum. Leaves of non-transgenic $N$. benthamiana plants, plants transformed with an 'empty' transformation vector (Control), or $T_{2}$ generation transformed plants expressing wild-type AOX (AOX1) or mutant AOX-E (AOX-E3) transgenes were infiltrated with solutions of salicylic acid (SA), antimycin $A(A A)$, or water $(\mathrm{W})$ containing $0.05 \%(v / V)$ ethanol (equivalent to the ethanol used to dissolve SA and AA before dilution). Within 10 min of infiltration, leaves were inoculated with TMV $(0.05 \mu \mathrm{g} / \mathrm{ml}$ in water). Arrows denote transgenic lines with increased $(\uparrow)$ or decreased $(\downarrow)$ alternative respiratory pathway (AP) capacities. A. Induction of resistance to TMV by AA ( $2 \mu M)$ in directly inoculated leaf tissue was inhibited in plants with increased AP capacity. However, induction of resistance to TMV by SA (2.5 mM) in directly inoculated leaf tissue was not appreciably inhibited in plants with an increased AP capacity. B. A concentration of SA $(0.5 \mathrm{mM})$ that was insufficient to induce resistance in non-transgenic leaves did induce resistance in plants with decreased AP capacity (line AOX-E3). AA at $2 \mu \mathrm{M}$ was sufficient to induce resistance in non-transgenic leaves and in plants with decreased AP capacity, but insufficient to do so in plants with increased AP capacity. Equal loading of lanes indicated by accumulation of ribulose-1, 5-bisphosphate carboxylase/oxygenase large subunit (LSU) was revealed by Ponceau S staining of immunoblot membranes.

resistance (in which plants are not susceptible to the pathogen) or provide some minimal level of resistance to infection (basal resistance) in susceptible plants. Typically, PAMPs are quite generic in their nature and for bacterial pathogens include fragments of flagellin or translation factors [56]. Baurès and colleagues [57] have theorized that in PVX and other potexviruses a highly conserved amino acid sequence or folded structure in the coat protein might function as a PAMP. It is also known that the PVX coat protein interacts with a factor, the RanGAP2 


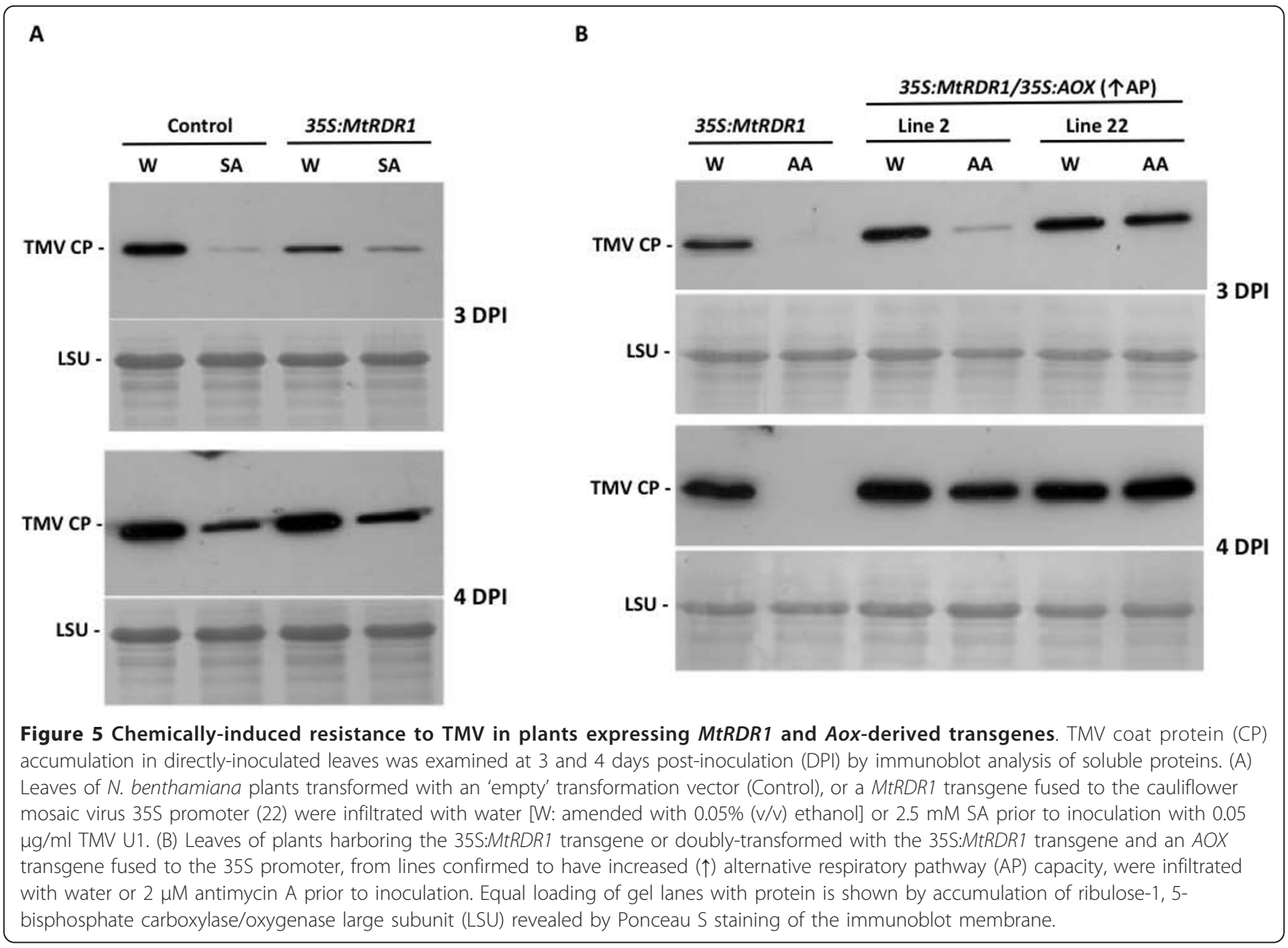

protein, which may act as a target or decoy for the PVX coat protein and (in plants harbouring the $R x$ resistance gene) may participate in triggering resistance [58-60]. It is possible that interactions of the PVX coat protein with an unknown receptor, or with RanGAP2 in susceptible plants (such as the $N$. benthamiana used in this study), result in induction of basal resistance mechanisms via the production of ROS. Maxwell and colleagues [36] showed that AOX can affect ROS levels throughout the cell, so it could be that this signaling mechanism is affected in plants with modified alternative respiration. Possibly consistent with this idea are observations showing that potexvirus infections are associated with complex changes in ROS and in the activity of anti-oxidant enzymes [61].

Our rationale for using $N$. benthamiana in this study was that the NbRDR1m gene encodes a protein that lacks RDR activity [22]. Thus, it was envisaged that we would be able to observe the effects of modifying alternative respiratory capacity on the effectiveness of SA-induced resistance to TMV without interference from RDR1 activity. However, we found that although antimycin A-induced resistance to TMV was affected in plants with either increased, or decreased, alternative respiratory capacity, SA-induced resistance to this virus was only affected (enhanced) in plants with a decreased capacity. The results are similar to those seen in transgenic tobacco plants with increased alternative pathway capacities [20]. Performing experiments with plants expressing MtRDR1 constitutively showed that although these plants are more resistant to systemic TMVinduced disease, the expression of this enzyme has no detectable effects on TMV accumulation in the directlyinoculated leaves or on chemically induced resistance in these tissues. Thus, our hypothesis that SA-induced resistance to TMV in tobacco could be a result of the combined action of AOX-regulated mechanisms and RDR1-mediated viral RNA turnover was overly simplistic. Our results with $N$. benthamiana do not rule out a role for RDR1 activity in SA-induced resistance to this virus, or a role for AOX as a regulator of this resistance. But the results indicate that additional, unknown factors also participate in SA-induced TMV resistance (Figure 6).

\section{Conclusions}

The study revealed that for PVX, SA-induced resistance is much simpler in its execution than SA-induced resistance to TMV. For PVX, AOX-modulated defensive 
signaling is the predominant factor in controlling SAinduced resistance. In conclusion, the results of this study show that AOX-regulated signaling constitutes an important part of plant antiviral resistance. However, it is also clear that the phenomena of SA-induced resistance and basal resistance to viruses both result from the operation of multiple antiviral mechanisms that do not inhibit all viruses to an equal extent.

\section{Methods}

\section{Plant Growth Conditions}

Seeds of Nicotiana benthamiana (Domin.) non-transgenic and transgenic plant lines were, as appropriate, germinated on soil or under sterile conditions on $1 \%$ (w/v) agar containing Murashige and Skoog medium (Melford Ltd, Ipswich, UK). For germination of transgenic seed, agar media were supplemented with kanamycin $\left(50 \mu \mathrm{g} \cdot \mathrm{ml}^{-1}\right)$, hygromycin B $\left(29 \mu \mathrm{g} \cdot \mathrm{ml}^{-1}\right)$, or both antibiotics as appropriate. After transfer to soil, all plants were maintained in a growth room (Conviron Ltd., Winnipeg, Manitoba, Canada) under a $16 \mathrm{~h}$ photoperiod $\left(200 \mu \mathrm{E} . \mathrm{m}^{-2} . \mathrm{s}^{-1}\right.$ of photosynthetically active radiation) at $22^{\circ} \mathrm{C}$ and $60 \%$ relative humidity.

\section{Generation of transgenic tobacco and $N$. benthamiana constitutively expressing wild-type and mutant Aox1a gene sequences}

Adapting a method previously used [45], pDJSnAOX-E was generated by mutagenesis of the Aox 1 cDNA insert of pDJSn [20] to replace the codon for the active site glutamate 221 with one for alanine using the oligonucleotides 5'-GAAGCTGAAAATGCCAGGATGCACCTC

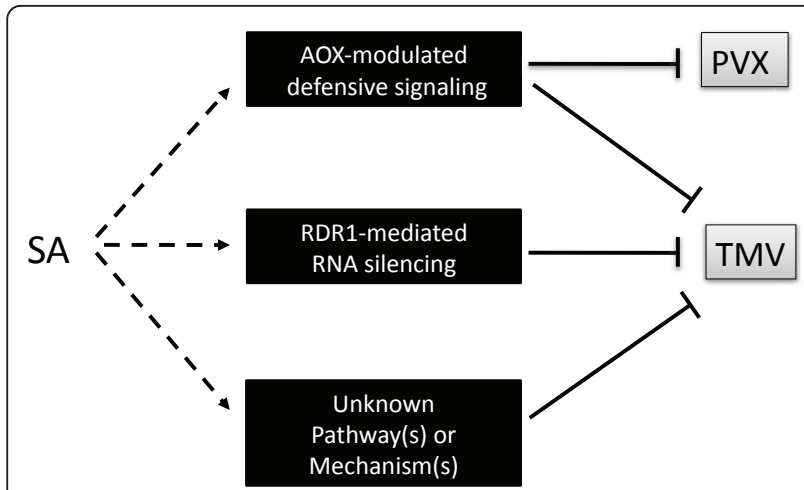

Figure $\mathbf{6}$ Induction of virus resistance by salicylic acid. Based on our data we propose that salicylic acid (SA)-mediated signaling (dashed arrows) induces several distinct mechanisms that inhibit (solid blunt-ended lines) virus infection. For some viruses,

exemplified by potato virus $X(P V X)$, anti-viral mechanisms regulated by alternative oxidase (AOX) play a predominant role. Other viruses, exemplified by tobacco mosaic virus (TMV), are affected not only by AOX-modulated mechanisms and RDR1-mediated antiviral RNA silencing but also by other, unknown mechanisms.
ATGAC-3' and 5'-GTCATGAGGTGCATCCTGGC ATTTTCAGCTTC-3', and the Stratagene Quikchange XL site-directed mutagenesis kit (http://www.stratagene. $\mathrm{com} /$ ). Agrobacterium tumefaciens strain GV3101 cells were transformed with DNA for pDJSn or PDJSnAOX-E using the freeze-thaw method [62]. The leaf disc method [63] was used for A. tumefaciens-mediated transformation of $N$. benthamiana and transgenic $N$. benthamiana harboring the 35S:MtRDR1 transgene [22]. Conditions used for transformation of $N$. benthamiana were similar to those used for tobacco [20], except that shooting and rooting media were modified to contain $1 \mu \mathrm{M}$ 1-naphthaleneacetic acid. Transformed lines were screened for transgene incorporation and expression using PCR and RT-PCR, respectively. Immunoblot analysis was used to detect constitutive AOX production and altered alternative respiratory pathway capacity was determined using established methods $[20,45,40,64]$. Lines of doubly-transformed plants derived from MtRDR1-transgenic plants that had been super-transformed with $\mathrm{pDJSn}$ were also checked for expression of the MtRDR1 by RT-PCR and using in vitro RDR activity assays as described by Xie et al. [19].

\section{Virus strains, detection of infection and chemical treatments}

TMV (Genus, Tobamovirus; Species, Tobacco mosaic virus) strain U1 [65] and PVX (Genus Potexvirus; Species Potato virus $X$ ) strain UK3 [66] were used in this study. Immunoblot detection of TMV and PVX using appropriate anti-coat protein sera followed a previously described method [67]. For quantification of PVX accumulation, leaf samples were homogenized as described by Murphy et al. [67] and used in double-antibody sandwich-ELISA [68] using reagents and antibodies and following instructions supplied by Bioreba (http://www.bioreba.ch/). Quantification was achieved with a standard curve using known amounts of purified virus. Data from transgenic plants were assessed for statistically-significant $(p<0.05)$ differences from nontransgenic controls using two-tailed t-tests [statistical software Genstat ${ }^{\circledR} 2010$ Thirteenth Edition, ${ }^{\circ}$ Lawes Agricultural Trust (Rothamsted Research), VSN International Ltd., Hemel Hempstead, UK.; [69]].

For whole-plant treatments with SA, five-to-six week old $N$. benthamiana plants were sprayed for four consecutive days with either a control solution $[0.05 \%(\mathrm{w} / \mathrm{v})$ ethanol] or $1 \mathrm{mM} \mathrm{SA}$ dissolved in $0.05 \%(\mathrm{w} / \mathrm{v})$ ethanol before rub inoculation with PVX or TMV on one or two lower leaves as previously described for tobacco $[11,20]$. Chemical treatment of leaf tissue by infiltration was carried out as described by Gilliland et al. [20] using SA or antimycin A concentrations described in Results and figure legends. 


\section{Additional material}

Additional file 1: Detection of AOX-E protein expression and overexpression of AOX protein in transgenic Nicotiana benthamiana plant lines used in this study. Immunoblot detection of AOX (A) or mutant AOX-E (B) present in non-transgenic (NT) N. benthamiana plants and $T_{2}$ generation transformed plants belonging to various independent lines (numbered) harboring AOX or AOX-E transgenes expressed under the control of the $35 \mathrm{~S}$ constitutive promoter. Equal amounts of Triton X100 soluble proteins were denatured in the presence of $0.1 \mathrm{M}$ dithiothreitol and subjected to immunoblot analysis using an anti-AOX monoclonal antibody. Anti-AOX binding was detected using anti-mouse immunoglobulin conjugated to horseradish peroxidase and a chemiluminescent substrate. A protein sample extracted from a plant of the Sn6 transgenic tobacco plant line, which over-expresses AOX (Murphy et al., 2004), served as the Positive Control. The major crossreacting band in all cases corresponded in size (apparent $\mathrm{Mr}$ c.35kDa) to the reduced form of AOX. Pre-stained Mr markers were not visible on the X-ray film. All lines express AOX or AOX-E at much higher levels than the native AOX protein which is not detectable on this western blot.

Additional file 2: Image showing TMV-induced systemic symptoms of TMV on non-transgenic, control transgenic and MtRDR1transgenic $\boldsymbol{N}$. benthamiana. Non-transgenic (NT) Nicotiana benthamiana plants, plants transformed with an 'empty' transformation vector (Control) and transgenic lines constitutively expressing MtRDR1 (35S:MtRDR1: Reference 22) were inoculated with TMV U1 strain $(0.05 \mathrm{ug} / \mathrm{ml})$ and photographed four weeks later. Mock-inoculated NT plants are shown for comparison. The scale bar is $8 \mathrm{~cm}$.

\section{Acknowledgements}

The authors thank Alex Murphy, Androulla Gilliland and Mat Lewsey for useful discussions and Zhixiang Chen for advice on performing in vitro RDR assays. We thank Rick Nelson for MtRDR1-expressing N. benthamiana and the transformed control line, Tom Elthon for anti-AOX monoclonal antibody, and Mike Wilson for anti-TMV CP polyclonal serum. FSF was funded by grants from the Cambridge Overseas Trust and the Ministry of Education of Taiwan, and WSL was funded by a studentship from the Biotechnology and Biological Sciences Research Council (BBSRC). JVL was funded by a USDA CSREES-NRI-2007-01530 Research Sabbatical Grant. Work in JPC's laboratory is supported by grants from The Leverhulme Trust (F/09 741/F), BBSRC (BB/ D008204/1; BB/F014376/1), the EU and the Cambridge University Isaac Newton Trust.

\section{Author details}

'Department of Plant Sciences, University of Cambridge, Downing Street, Cambridge CB2 3EA, UK. ${ }^{2}$ Oklahoma State University, Department of Entomology and Plant Pathology, 127 Noble Research Center, Stillwater, OK 74078, USA.

\section{Authors' contributions}

WSL and FSF carried out the experimental procedures, with additional experiments by JVL on PVX accumulation. JPC initiated and directed the research and wrote the manuscript. All authors read and approved the final manuscript.

Received: 13 December 2010 Accepted: 28 February 2011 Published: 28 February 2011

\section{References}

1. Carr JP, Lewsey MG, Palukaitis P: Signaling in induced resistance. Adv Virus Res 2010, 76:57-121.

2. Gaffney T, Friedrich L, Vernooij B, Negrotto D, Nye G, Uknes S, Ward E, Kessmann $H$, Ryals J: Requirement of salicylic acid for the induction of systemic acquired resistance. Science 1993, 261:754-756.

3. Hammerschmidt R: Systemic acquired resistance. Adv Bot Res 2009, 51:173-222.

4. Király L, Hafez YM, Fodor J, Király Z: Suppression of tobacco mosaic virusinduced hypersensitive-type necrotization in tobacco at high temperature is associated with downregulation of NADPH oxidase and superoxide and stimulation of dehydroascorbate reductase. I Gen Virol 2008, 89:799-808.

5. Loebenstein G: Local lesions and induced resistance. Adv Virus Res 2009, 75:73-117

6. Malamy J, Carr JP, Klessig DF, Raskin I: Salicylic acid- A likely endogenous signal in the resistance response of tobacco to viral infection. Science 1990, 250:1002-1004.

7. Métraux JP, Signer H, Ryals J, Ward E, Wyss-Benz M, Gaudin J, Raschdorf K Schmid E, Blum W, Inverardi B: Increase in salicylic acid at the onset of systemic acquired resistance in cucumber. Science 1990, 250:1004-1006.

8. Mur LAJ, Bi YM, Darby RM, Firek S, Draper J: Compromising early salicylic acid accumulation delays the hypersensitive response and increases viral dispersal during lesion establishment in TMV-infected tobacco. Plant J 1997, 12:1113-1126.

9. Chivasa S, Carr JP: Cyanide restores $N$ gene-mediated resistance to tobacco mosaic virus in transgenic tobacco expressing salicylic acid hydroxylase. Plant Cell 1998, 10:1489-1498.

10. Chivasa S, Murphy AM, Naylor M, Carr JP: Salicylic acid interferes with tobacco mosaic virus replication via a novel, salicylhydroxamic acidsensitive mechanism. Plant Cell 1997, 9:547-557.

11. Naylor M, Murphy AM, Berry JO, Carr JP: Salicylic acid can induce resistance to plant virus movement. Mol Plant-Microbe Interact 1998, 11:860-868.

12. Love AJ, Yun BW, Laval V, Loake GJ, Milner JJ: Cauliflower mosaic virus, a compatible pathogen of Arabidopsis, engages three distinct defensesignaling pathways and activates rapid systemic generation of reactive oxygen species. Plant Physiol 2005, 139:935-948.

13. Love AJ, Laval V, Geri C, Laird J, Tomos AD, Hooks MA, Milner JJ: Components of Arabidopsis defense- and ethylene-signaling pathways regulate susceptibility to Cauliflower mosaic virus by restricting longdistance movement. Mol. Plant-Microbe Interact 2007, 20:659-670.

14. Murphy AM, Carr JP: Salicylic acid has cell-specific effects on Tobacco mosaic virus replication and cell-to-cell movement. Plant Physiol 2002, 128:552-563.

15. Wong CE, Carson RA, Carr JP: Chemically induced virus resistance in Arabidopsis thaliana is independent of pathogenesis-related protein expression and the NPR1 gene. Mol Plant-Microbe Interact 2002, 15:75-81.

16. Mayers CN, Lee KC, Moore CA, Wong SM, Carr JP: Salicylic acid induced resistance to Cucumber mosaic virus in squash and Arabidopsis thaliana: Contrasting mechanisms of induction and antiviral action. Mol PlantMicrobe Interact 2005, 18:428-434.

17. Lewsey MG, Carr JP: DICER-LIKE proteins 2,3 and 4 are not essential for salicylic acid-mediated resistance against two RNA viruses. J Gen Virol 2009, 90:3010-3014.

18. Csorba T, Pantaleo V, Burgyán J: RNA silencing: An antiviral mechanism. Adv Virus Res 2009, 75:35-71.

19. Xie Z, Fan B, Chen C, Chen Z: An important role of an inducible RNAdependent RNA polymerase in plant antiviral defense. Proc Natl Acad Sci USA 2001, 98:6516-6521.

20. Gilliland A, Singh DP, Hayward JM, Moore CA, Murphy AM, York CJ, Slator J, Carr JP: Genetic modification of alternative respiration has differential effects on antimycin A-induced versus salicylic acid-induced resistance to Tobacco mosaic virus. Plant Physiol 2003, 132:1518-1528.

21. Yu D, Fan B, MacFarlane SA, Chen Z: Analysis of the involvement of an inducible Arabidopsis RNA-dependent RNA polymerase in antiviral defense. Molec Plant-Microbe Interact 2003, 16:206-216.

22. Yang SJ, Carter SA, Cole AB, Cheng NH, Nelson RS: A natural variant of a host RNA-dependent RNA polymerase is associated with increased susceptibility to viruses by Nicotiana benthamiana. Proc Natl Acad Sci USA 2004, 101:6297-6302.

23. Pandey SP, Baldwin IT: RNA-directed RNA polymerase 1 (RdR1) mediates the resistance of Nicotiana attenuata to herbivore attack in nature. Plant J 2007, 50:40-53.

24. Rakhshandehroo F, Takeshita M, Squires J, Palukaitis $P$ : The influence of RNAdependent RNA polymerase 1 on Potato virus $Y$ infection and on other antiviral response genes. Mol Plant-Microbe Interact 2009, 22:1312-1318.

25. Ji L-H, Ding SW: The suppressor of transgene RNA silencing encoded by Cucumber mosaic virus interferes with salicylic acid-mediated virus resistance. Mol Plant-Microbe Interact 2001, 14:715-724. 
26. Krečič-Stres H, Vucak C, Ravnikar M, Kovač M: Systemic Potato virus Y YTN infection and levels of salicylic and gentisic acids in different potato genotypes. Plant Pathology 2005, 54:441-447.

27. Alamillo JM, Saénz P, Garć́a JA: Salicylic acid-mediated and RNA-silencing defense mechanisms cooperate in the restriction of systemic spread of plum pox virus in tobacco. Plant $J$ 2006, 48:217-227.

28. Lewsey MG, Murphy AM, MacLean D, Dalchau N, Westwood JH, Macaulay K, Bennett MH, Moulin M, Hanke DE, Powell G, Smith AG, Carr JP: Disruption of two defensive signaling pathways by a viral RNA silencing suppressor. Molec Plant-Microbe Interact 2010, 23:835-845.

29. Noctor $\mathrm{G}$, Foyer $\mathrm{CH}$ : Ascorbate and glutathione keeping active oxygen under control. Ann Rev Plant Physiol Plant Mol Biol 1998, 49:249-279.

30. Yip JYH, Vanlerberghe GC: Mitochondrial alternative oxidase acts to dampen the generation of active oxygen species during a period of rapid respiration induced to support a high rate of nutrient uptake. Physiologia Plantarum 2001, 112:327-333.

31. Noctor G, De Paepe R, Foyer CH: Mitochondrial redox biology and homeostasis in plants. Trends Plant Sci 2007, 12:125-134.

32. Maxwell DP, Nickels R, McIntosh L: Evidence of mitochondrial involvement in the transduction of signals required for the induction of genes associated with pathogen attack and senescence. Plant J 2002, 29:269-279.

33. Umbach AL, Fiorani F, Siedow JN: Characterization of transformed Arabidopsis with altered alternative oxidase levels and analysis of effects on reactive oxygen species in tissue. Plant Physiol 2005, 139:1806-1820.

34. Rhoads DM, Umbach AL, Subbiah CC, Siedow JN: Mitochondrial reactive oxygen species. Contribution to oxidative stress and interorganellar signalling. Plant Physiol 2006, 141:357-366.

35. Rhoads DM, Subbiah CC: Mitochondrial retrograde regulation in plants. Mitochondrion 2007, 7:177-194.

36. Maxwell DP, Wang $Y$, McIntosh $L$ : The alternative oxidase lowers mitochondrial reactive oxygen production in plant cells. Proc Natl Acad Sci USA 1999, 96:8271-8276.

37. Affourtit $C$, Krab K, Moore AL: Control of plant mitochondrial respiration. Biochimica et Biophysica Acta- Bioenergetics 2001, 1504:58-69.

38. Affourtit C, Albury MSW, Crichton PG, Moore AL: Exploring the molecular nature of alternative oxidase regulation and catalysis. FEBS Lett 2002, 510:121-126.

39. Moore AL, Albury MS, Crichton PG, Affourtit C: Function of the alternative oxidase: Is it still a scavenger? Trends Plant SCi 2002, 7:478-481.

40. Pasqualini S, Paolocci F, Borgogni A, Morettini R, Ederli L: The overexpression of an alternative oxidase gene triggers ozone sensitivity in tobacco plants. Plant Cell Environ 2007, 30:1545-1556.

41. Wang J, Wang X, Liu C, Zhang JD, Zhu CX, Gu XQ: The NgAOX1a gene cloned from Nicotiana glutinosa is implicated in the response to abiotic and biotic stresses. Biosci Rep 2008, 28:259-266.

42. Fu L, Shi K, Gu M, Zhou YH, Dong DK, Liang WS, Song FM, Yu JQ: Systemic induction and role of mitochondrial alternative oxidase and nitric oxide in a compatible tomato-Tobacco mosaic virus interaction. Molec Plant-Microbe Interact 2010, 23:39-48.

43. Xie Z, Chen Z: Salicylic acid induces rapid inhibition of mitochondrial electron transport and oxidative phosphorylation in tobacco cells. Plant Physiol 1999, 120:217-225.

44. Norman C, Howell KA, Millar AH, Whelan JM, Day DA: Salicylic acid is an uncoupler and inhibitor of mitochondrial electron transport. Plant Physiol 2004, 134:492-501.

45. Murphy AM, Gilliland A, York CJ, Hyman B, Carr JP: High-level expression of alternative oxidase protein sequences enhances the spread of viral vectors in resistant and susceptible plants. J Gen Virol 2004, 85:3777-3786.

46. Singh DP, Moore CA, Gilliland A, Carr JP: Activation of multiple antiviral defence mechanisms by salicylic acid. Mol Plant Pathol 2004, 5:57-63.

47. Herskowitz I: Functional inactivation of genes by dominant negative mutations. Nature 1987, 329:219-222.

48. Goodin MM, Zaitlin D, Naidu RA, Lommel SA: Nicotiana benthamiana: Its history and future as a model for plant-pathogen interactions. Molec Plant-Microbe Interact 2008, 21:1015-1026.

49. Henning J, Malamy J, Grynkiewicz G, Indulski J, Klessig DF: Interconversion of the salicylic acid signal and its glucoside in tobacco. Plant J 1992, 4:593-600
50. Ordog SH, Higgins VJ, Vanlerberghe GC: Mitochondrial alternative oxidase is not a critical component of plant viral resistance but may play a role in the hypersensitive response. Plant Physiol 2002, 129:1858-1865.

51. Schwach F, Vaistij FE, Jones L, Baulcombe DC: An RNA dependent RNA polymerase prevents meristem invasion by potato virus $X$ and is required for the activity but not the production of a systemic silencing signal. Plant Physiol 2005, 138:1842-1852.

52. Verchot-Lubicz J, Ye CM, Bamunusinghe D: Molecular biology of the potexviruses: Recent advances. J Gen Virol 2007, 88:1643-1655.

53. Verchot-Lubicz J: A new cell-to-cell transport model for Potexviruses. Molec Plant-Microbe Interact 2005, 18:283-229.

54. Wang X, Goregaoker SP, Culver JN: Interaction of the Tobacco mosaic virus replicase protein with a NAC domain transcription factor is associated with the suppression of systemic host defenses. J Virol 2009, 83:9720-9730.

55. Boller T, He S-Y: Innate immunity in plants: An arms race between pattern recognition receptors in plants and effectors in microbial pathogens. Science 2009, 324:742-744.

56. Lindeberg M, Cunnac S, Collmer A: The evolution of Pseudomonas syringae host specificity and Type III effector repertoires. Mol Plant Pathol 2009, 10:767-775.

57. Baurès I, Candresse T, Leveau A, Bendahmane A, Sturbois B: The Rx gene confers resistance to a range of Potexviruses in transgenic Nicotiana plants. Mol Plant-Microbe Interact 2008, 21:1154-1164.

58. Sacco MA, Mansoor S, Moffett P: A RanGAP protein physically interacts with the NB-LRR protein $R x$, and is required for Rx-mediated viral resistance. Plant J 2007, 52:82-93.

59. Tameling WIL, Baulcombe DC: Physical association of the NB-LRR resistance protein $\mathrm{Rx}$ with a Ran GTPase-activating protein is required for extreme resistance to Potato virus X. Plant Cell 2007, 19:1682-1694.

60. Moffett P: Mechanisms of recognition in $R$ gene mediated resistance. Adv Virus Res 2009, 75:2-33.

61. Clarke SF, Guy PL, Burritt DJ, Jameson PE: Changes in the activities of antioxidant enzymes in response to virus infection and hormone treatment. Physiologia Plantarum 2002, 114:157-164.

62. Holsters M, de Waele D, Depicker A, van Montagu M, Schell J: Transfection and transformation of Agrobacterium tumefaciens. Molec Gen Genetics 1978, 163:181-187.

63. Horsch RB, Fry JE, Hoffman NL, Eichholz D, Rogers SG, Fraley RT: A simple and general method for transferring genes into plants. Science 1985, 227:1229-1231.

64. Elthon TE, Nickels RL, McIntosh L: Monoclonal antibodies to the alternative oxidase of higher plant mitochondria. Plant Physiol 1989, 89:1311-1317.

65. Carr JP: Tobacco mosaic virus. In Plant-Pathogen Interactions. Edited by: Talbot NJ. Blackwell, Oxford; 2004:27-67.

66. Köhm BA, Goulden MG, Gilbert JE, Kavanaugh TA, Baulcombe DC: A potato virus $\mathrm{X}$ resistance gene mediates an induced, non-specific resistance in protoplasts. Plant Cell 1993, 5:913-920.

67. Murphy AM, Otto B, Brearley CA, Carr JP, Hanke DE: A role for inositol hexakisphosphate in the maintenance of basal resistance to plant pathogens. Plant J 2008, 56:638-652.

68. Barbara DJ, Clark MF: A simple indirect ELISA using $F\left(a b^{\prime}\right)_{2}$ fragments of immunoglobulin. J Gen Virol 1982, 58:315-322.

69. Payne RW, Harding SA, Murray DA, Soutar DM, Baird DB, Glaser Al, Channing IC, Welham SJ, Gilmour AR, Thompson R, Webster R: The guide to Genstat release 13, Part 2: Statistics. Oxford: VSN International; 2010.

doi:10.1186/1471-2229-11-41

Cite this article as: Lee et al:: Genetic modification of alternative respiration in Nicotiana benthamiana affects basal and salicylic acidinduced resistance to potato virus X. BMC Plant Biology 2011 11:41. 